\title{
Evidence for the association of the SLC22A4 and SLC22A5 genes with Type I Diabetes: a case control study
} Jose Luis Santiago ${ }^{1}$, Alfonso Martínez ${ }^{1}$, Hermenegildo de la Calle ${ }^{2}$, Miguel Fernández-Arquero' ${ }^{1}$ M Ángeles Figueredo ${ }^{1}$, Emilio G de la Concha*1 and Elena Urcelay ${ }^{1}$

Address: ${ }^{1}$ Immunology Department, Hospital Universitario San Carlos, Madrid, Spain and ${ }^{2}$ Endocrinology Department, Hospital Ramón y Cajal, Madrid, Spain

Email: Jose Luis Santiago - jlsanti@hotmail.com; Alfonso Martínez - alfmdoncel@terra.es; Hermenegildo de la Calle - hcalle.hrc@salud.madrid.org; Miguel Fernández-Arquero - mfernandeza.hcsc@salud.madrid.org; M Ángeles Figueredo - mfigueredo.hcsc@salud.madrid.org; Emilio G de la Concha* - egomezdela.hcsc@salud.madrid.org; Elena Urcelay - eurcelay.hcsc@salud.madrid.org

* Corresponding author

Published: 23 June 2006

BMC Medical Genetics 2006, 7:54 doi:10.1 186/147|-2350-7-54
Received: II April 2006

Accepted: 23 June 2006

This article is available from: http://www.biomedcentral.com/I47/-2350/7/54

(c) 2006 Santiago et al; licensee BioMed Central Ltd.

This is an Open Access article distributed under the terms of the Creative Commons Attribution License (http://creativecommons.org/licenses/by/2.0), which permits unrestricted use, distribution, and reproduction in any medium, provided the original work is properly cited.

\begin{abstract}
Background: Type I diabetes (TID) is a chronic, autoimmune and multifactorial disease characterized by abnormal metabolism of carbohydrate and fat. Diminished carnitine plasma levels have been previously reported in TID patients and carnitine increases the sensitivity of the cells to insulin. Polymorphisms in the carnitine transporters, encoded by the SLC22A4 and SLC22A5 genes, have been involved in susceptibility to two other autoimmune diseases, rheumatoid arthritis and Crohn's disease. For these reasons, we investigated for the first time the association with TID of six single nucleotide polymorphisms (SNPs) mapping to these candidate genes: slc2F2, slc2FII, T3061, L503F, OCTN2-promoter and OCTN2-intron.
\end{abstract}

Methods: A case-control study was performed in the Spanish population with 295 TID patients and 508 healthy control subjects. Maximum-likelihood haplotype frequencies were estimated by applying the Expectation-Maximization (EM) algorithm implemented by the Arlequin software.

Results: When independently analyzed, one of the tested polymorphisms in the SLC22A4 gene at 1672 showed significant association with TID in our Spanish cohort. The overall comparison of the inferred haplotypes was significantly different between patients and controls $\left(\chi^{2}=10.43 ; p=0.034\right)$ with one of the haplotypes showing a protective effect for TID (rs3792876/rs I050 I52/rs263। 367/ rs274559, CCGA: OR = $0.62(0.4 \mathrm{I}-0.93) ; \mathrm{p}=0.02)$.

Conclusion: The haplotype distribution in the carnitine transporter locus seems to be significantly different between TID patients and controls; however, additional studies in independent populations would allow to confirm the role of these genes in TID risk. 


\section{Background}

Type 1 diabetes (T1D) is a multifactorial autoimmune Tcell-mediated disease resulting from selective destruction of the insulin producing $\beta$ cells in the pancreatic islets, leading to an absolute insulin deficiency. The risk of developing T1D is determined by a complex interaction between multiple genetic and environmental factors. Although susceptibility to disease is strongly associated with alleles in the major histocompatibility complex (MHC) [1,2], there are more than 20 putative T1D susceptibility regions identified by linkage and association studies $[3,4]$. At present, several non-MHC susceptibility loci with modest genetic effects have been clearly defined. However, it is well known that many non-MHC loci predisposing to T1D remain as yet undefined [5].

Type 1 diabetes is a chronic degenerative disease, with altered metabolism characterized by hyperglycemia and ketoacidosis and T1D patients depend on exogenous insulin to sustain life. The role of the carnitine system in cell metabolism is mainly known in the mitochondria, where the interaction between fatty acid and glucose metabolism is fundamental for cell energy production [6,7]. However, carnitine not only contributes to the transport of activated long-chain fatty acids into mitochondria for $\beta$-oxidation, but it also increases the sensitivity of cells to insulin [8]. Decreased plasma carnitine levels have been reported in patients with type 2 diabetes [9-11] and some studies have investigated the carnitine status in T1D, finding similar results [12-15].

Adequate carnitine levels are required for normal lipid metabolism and are important for energy metabolism [16]. One important component of the carnitine system is the plasma membrane carnitine transporters, named organic cation transporters (OCTN1 and OCTN2) encoded by the SLC22A4 and SLC22A5 genes, respectively. Both genes map to the cytokine gene cluster on chromosome 5q31 and show 88\% homology and 77\% identity in their sequences. Despite OCTN1 and OCTN2 are considered as carnitine transporters, only OCTN2 is a high-affinity human carnitine transporter, while the carnitine transport activity of OCTN1 is very low $[17,18]$. In fact, a recent study has reported that the main substrate of this transporter is the ergothioneine, an intracellular antioxidant with metal ion affinity, which is transported one hundred times more efficiently than carnitine [18]. OCTN2 is widely expressed in many adult tissues, among them in pancreas, and it participates, at least in part, in proton/organic cation antiport at the renal apical plasma membrane level [19].

Recent reports performed associations of some polymorphisms within the SLC22A4 and SLC22A5 genes with two other autoimmune complex diseases (rheumatoid arthri- tis and Crohn's disease) $[20,21]$. The purpose of this study was to investigate the influence of the SLC22A4 and SLC22A5 genes in type 1 diabetes risk in the Spanish population. Six SNPs along these genes were considered good markers to map this region: slc2F2 (rs3792876) and slc2F11 (rs 2306772), which are SNPs in the SLC22A4 gene, were originally associated with RA susceptibility [20]. Other polymorphisms within the same linkage disequilibrium (LD) block (slc2F1) and slc2F2 showed lack of association with T1D [22]. We have studied two additional SNPs in this gene: T306I (rs272893) and L503F (rs1050152, SNP located in exon 9 of SLC22A4). The OCTN2-promoter (rs2631367) is a transversion ($207 \mathrm{G}>\mathrm{C}$ ) disrupting a heat shock element in the promoter region of the SLC22A5 gene and it has been described, together with L503F, as etiologic variant in Crohn disease [21]. Finally, we analyzed an intronic SNP in the SLC22A5 gene: the OCTN2-intron (rs274559) in order to define haplotypes within these genes.

\section{Methods \\ Patients}

We studied 295 unrelated Spanish white T1D patients (149 men and 146 women) diagnosed according to the criteria of the American Diabetes Association (ADA) and 508 healthy controls recruited among blood donors. Both groups ethnically matched from the Madrid area. The age at onset for the T1D patients range from 1 to 55 years old (median age at onset 15 years) and all subjects were insulin-dependent at the time to study. The protocol followed the principles expressed in the Declaration of Helsinki and it was approved by the Hospital Ethics Committee.

\section{SNP genotyping}

SNPs slc2F2 (rs3792876), slc2F11 (rs2306772), T306I (rs272893), L503F (rs1050152) and OCTN2-intron (rs274559) were genotyped by TaqMan Assays on Demand under conditions recommended by manufacturer (Applied Biosystems), with identification numbers: C_3170428_10, C_3170458_1_, C_3170445_1_, C_3170459_10 and C_1173605_1, respectively. For the SLC22A5 promoter -207G>C (rs2631367), a TaqMan Assay by Design was performed.

\section{Statistical analysis}

Differences in allele or genotype frequencies for each marker were calculated by Chi-square, or Fisher's exact test when necessary. Associations were estimated by the odds ratio (OR) with 95\% confidence interval (CI). Statistical analysis used Epi Info v. 6.02 (CDC Atlanta USA).

Maximum-likelihood haplotype frequencies were estimated by applying the Expectation Maximization (EM) algorithm implemented by the Arlequin software [23], with number of iterations set at 5000 and initial condi- 


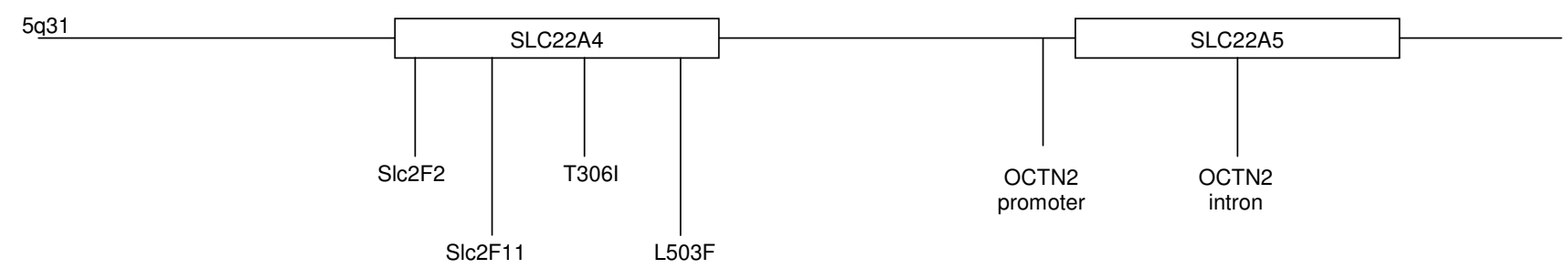

Figure I

Schematic representation of the chromosomal region $5 q 31$ with the relative position of the polymorphisms studied.

tions at 50, with an epsilon value of $10^{-7}$. This software yields the estimated frequency of each haplotype, but it does not output the expected haplotypes for each individual. The frequency data were transformed into absolute numbers multiplying the frequencies presented in Table 3 by the total number of haplotypes in each group (patients and controls). Then, these values were introduced into contingency tables to calculate Chi-square and p-values.

\section{Results}

Six SNPs were studied in order to check the role of SLC22A4 and SLC22A5 genes in T1D predisposition (see figure 1). Slc2F2, Slc2F11, T306I and L503F map in the SLC22A4 gene and two additional SNPs, OCTN2-promoter and OCTN2-intron, are located in the SLC22A5 gene. The analysis of the control cohort showed complete linkage disequilibrium (LD) between Slc2F11 and slc2F2, and T306I was also found in complete LD with OCTN2intron. Both SNPs (slc2F11 and T306I) were not considered in the subsequent case-control study, because they do not supply additional information. These polymorphisms conformed to Hardy-Weinberg equilibrium.

The association of the intronic slc2F2 polymorphism in the SLC22A4 gene with rheumatoid arthritis (RA) was originally reported in a Japanese population [20]. This SNP was even described as an etiological variant in Japan, being the mutant homozygous genotype (slc2F2*TT) associated with RA. However, this association could not be replicated either in British [24] or in Spanish populations [25]. Table 1 shows the phenotype and genotype distribution of this marker in the Spanish T1D patient and control cohorts, and lack of significant association with the disease was observed. The allelic distribution was similar to that previously observed in Spanish RA patients, (minor allele frequency slc2F2*T was $7.5 \%$ in RA and $9.5 \%$ in T1D patients). We tested the carrier rate of this allele (CT+TT vs. CC) to find a possible association with T1D, but a negative result was again obtained: $\mathrm{OR}=1.30$ (0.87-1.94); $\mathrm{p}=0.17$.
Regarding the L503F (1672G>C) polymorphism, it was described by Peltekova et al. [21] as a functional variant associated with Crohn's disease, together with the OCTN2-promoter $(-207 \mathrm{G}>\mathrm{C})$ variant. In fact, the authors found that the odds ratios conferred by the allele $1672 * \mathrm{~T}$, by the allele $-207^{*} \mathrm{C}$ or by the TC minihaplotype were all similar. Both polymorphisms were also in strong linkage disequilibrium in our population $\left(D^{\prime}=0.86\right)$ [26]. However, their etiological role could not be verified in Spanish Crohn's patients and they were not described as causative polymorphisms, but as genetic markers of risk or protection haplotypes. In our diabetic population, the allele $1672 * \mathrm{~T}$ increased disease predisposition $[\mathrm{OR}=1.25$ (1.01-1.54); $\mathrm{p}=0.034]$ and the $1672 * \mathrm{CC}$ genotype showed a protective effect (Table 1 ), but no significant differences between patients and controls were found for alleles and genotypes of the OCTN2-promoter (-207G>C) and of the other SLC22A5 intronic variant (Table 2).

We continued our study by analyzing the inferred OCTN1-OCTN2 haplotypes, since haplotypes define better a DNA fragment where a susceptibility or protective gene could be located. Table 3 shows the haplotypes estimated by the Expectation-Maximization (EM) algorithm implemented by the Arlequin software with a frequency over $1 \%$. The overall comparison of haplotypes in a $5 \times 2$ contingency table rendered a significant difference between patients and healthy controls $\left(\chi^{2}=10.43\right.$; $\mathrm{p}=$ 0.034 ), and being a unique omnibus comparison, this result does not need ulterior correction. These results evidenced one protection CCGA [OR $=0.62(0.41-0.93) ; \mathrm{p}=$ 0.02 ] and another risk CTCA [OR $=1.23(1.00-1.52) ; \mathrm{p}=$ 0.05 ] haplotypes, although they did not withstand correction for multiple testing (Table 3). The effect of the latter is secondary to the protective haplotype, as evidenced when this one is eliminated from the comparison and no significant predisposition effect was observed [OR $=1.16$ (0.93-1.44); $\mathrm{p}=0.18]$; however, when the eliminated haplotipe is CTCA, a significant protection effect is still found for the CCGA haplotype $[\mathrm{OR}=0.67(0.44-1.02)$; $\mathrm{p}$ 
Table I: Genotype and phenotype frequency distribution for OCTNI markers.

\begin{tabular}{ccc}
\hline SIc2F2 & TID (\%) & Controls (\%) \\
\hline Alleles & $2 n=590$ & $2 n=1016$ \\
C & $534(90.5)$ & $938(92.3)$ \\
T & $56(9.5)$ & $78(7.7)$ \\
Genotypes & $n=295$ & $n=508$ \\
CC & $240(81.4)$ & $432(85)$ \\
CT & $54(18.3)$ & $74(14.6)$ \\
TT & I (0.3) & $2(0.4)$ \\
& TID (\%) & Controls $(\%)$ \\
L503F & & \\
& $2 n=590$ & $2 n=970$ \\
Alleles & $299(50.7)$ & $545(56.2)$ \\
C & $29 I(49.3)$ & $425(43.8)$ \\
T & $n=295$ & $n=485$ \\
Genotypes & $69(23.4)$ & $156(32.2)$ \\
CC* & $16 I(54.6)$ & $233(48.0)$ \\
CT & $65(22.0)$ & $96(19.8)$ \\
TT &
\end{tabular}

$* O R=0.64(0.46-0.91) ; p=0.009$

$=0.047)$. Moreover, as other haplotypes carrying the $1672{ }^{*} \mathrm{C}$ allele do not show any influence in T1D predisposition, the protective effect of the $1672 * \mathrm{C}$ allele $(\mathrm{p}=$ 0.034 ) is due to this CCGA haplotype.

To complete the study in our population, we analyzed children and adolescents with type 1 diabetes fixing the cut-off age in 15 years old (median age at onset in our cohort). No differences between young patients and either adult patients or controls were found for any isolated variant or for the inferred haplotypes (data not shown). Finally, the frequencies of both, polymorphisms and

Table 2: Distribution of OCTN2 polymorphisms.

\begin{tabular}{ccc}
\hline OCTN2 Promoter & TID (\%) & Controls (\%) \\
\hline Alleles & $2 n=590$ & $2 n=1016$ \\
C & $327(55.4)$ & $533(52.5)$ \\
G & $263(44.6)$ & $483(47.5)$ \\
Genotypes & $n=295$ & $n=508$ \\
CC & $91(30.8)$ & $150(29.5)$ \\
CG & $145(49.2)$ & $233(45.9)$ \\
GG & $59(20.0)$ & $125(24.6)$ \\
OCTN2 Intron & TID (\%) & Controls $(\%)$ \\
\hline Alleles & $2 n=590$ & $2 n=1016$ \\
A & $370(62.7)$ & $636(62.6)$ \\
G & $220(37.3)$ & $380(37.4)$ \\
Genotypes & $n=295$ & $n=508$ \\
AA & $115(39.0)$ & $194(38.2)$ \\
AG & $142(48.1)$ & $248(48.8)$ \\
GG & $38(12.9)$ & $66(13.0)$ \\
\hline
\end{tabular}

inferred haplotypes, between male and female T1D patients were similar (data not shown).

\section{Discussion}

The chromosomal region 5q31 contains several genes involved in immune and inflammatory responses and the SLC22A4 and SLC22A5 genes were associated with two autoimmune diseases (rheumatoid arthritis and Crohn's disease) [20,21]. Additionally, several genomewide scans for type 1 diabetes have identified susceptibility loci on different chromosomes, including the region $5 q[27,28]$. Moreover, carnitine has been described to increase sensitivity of cells to insulin [8], which could hypothetically lend cells more prone to an autoimmune attack. For all these reasons we considered that these genes could be candidates to modify the susceptibility to another autoimmune disease, as type 1 diabetes.

We tested six polymorphisms in the SLC22A4 and SLC22A5 genes and in five of them no significant independent association with type 1 diabetes could be found (Tables 1 and 2). The power of this study considering a relative risk of 1.5 was $75 \%$ for Slc $2 \mathrm{~F} 2,86 \%$ for $\mathrm{L} 503 \mathrm{~F}$ and $99 \%$ for OCTN2-promoter and OCTN2-intron, as calculated by an UCLA Department of Statistics sofware [29]. Therefore, we can exclude the studied SLC22A5 markers as causative candidates for T1D in Spanish patients, but in the case of Slc2F2 our results are not conclusive, albeit a recently published study does not find association of Slc2F1 and Slc2F2 SLC22A4 polymorphisms within a well-powered T1D cohort [22], in agreement with our data.

The overall distribution of the estimated haplotypes was significantly different between patients and healthy controls. Being ours the first study carried out in T1D, replication studies in different T1D populations would be necessary to firmly establish the role of these genes in autoimmune diabetes. We proved by using a stepwise procedure that the association with T1D of the protection haplotype CCGA is primary. The etiological polymorphisms previously found associated with increased susceptibility to RA (slc2F2*T) and to Crohn's disease (L503F*T) do not display a causative role by themselves in our population.

Low carnitine plasma levels have been found in children and adolescents with type 1 diabetes $[12,13,15]$. For this reason, we decided to conclude the study with an agestratified analysis. No significant differences in the association of each polymorphism were observed when grouping by age at onset or gender. In the study of the inferred haplotypes again no differences were found between any group of patients and when we compared each group with controls. Therefore, it seems that the protective effect of 
Table 3: The main haplotypes in region of OCTNI and OCTN2 genes.

\begin{tabular}{|c|c|c|c|c|c|c|c|c|c|}
\hline \multirow[b]{2}{*}{ Slc2F2 } & \multirow[b]{2}{*}{ L503F } & \multirow[b]{2}{*}{$\begin{array}{l}\text { OCTN2 } \\
\text { Promoter }\end{array}$} & \multirow[b]{2}{*}{$\begin{array}{l}\text { OCTN2 } \\
\text { Intron }\end{array}$} & \multicolumn{2}{|c|}{ TID $(2 n=590)$} & \multicolumn{2}{|c|}{ Controls $(2 n=970)$} & \multirow[b]{2}{*}{ OR } & \multirow[b]{2}{*}{$\mathrm{P}$} \\
\hline & & & & Frequency & Haplotype & Frequency & Haplotype & & \\
\hline C & $\mathrm{T}$ & C & $A$ & 0.47853 & 282 & 0.42690 & $4 \mid 4$ & 1.23 & 0.05 \\
\hline C & C & $\mathrm{G}$ & $\mathrm{G}$ & 0.27276 & 161 & 0.29604 & 287 & 0.89 & 0.33 \\
\hline C & C & $\mathrm{G}$ & $A$ & 0.06522 & 38 & 0.10018 & 97 & 0.62 & 0.02 \\
\hline C & $\mathrm{C}$ & $\mathrm{C}$ & $A$ & 0.07388 & 44 & 0.08832 & 86 & 0.83 & 0.33 \\
\hline $\mathrm{T}$ & $\mathrm{C}$ & $\mathrm{G}$ & $\mathrm{G}$ & 0.09492 & 56 & 0.07732 & 75 & 1.25 & 0.22 \\
\hline
\end{tabular}

Overall comparison between patients and controls: $\chi^{2}=10.43 ; p=0.034$

the inferred haplotype is independent of both sex and age at disease onset.

A previous report about disequilibrium blocks at $5 q 31$ in European-derived population [30] demonstrated limited haplotype diversity, concordantly with our data ( 5 haplotypes found out of the $2^{4}=16$ theoretically possible). One of the defined blocks ( $92 \mathrm{~kb}$ long) corresponds to the carnitine transporter genes locus. These authors indicated that the chromosomal region $5 \mathrm{q} 31$ is divided into discrete blocks displaying complete linkage disequilibrium (LD). However, some degree of LD extending beyond the SLC22A4 and SLC22A5 genes could imply that most probably these genes, or other in LD with them, are responsible for the reported effect on T1D risk.

\section{Conclusion}

In conclusion, the overall comparison of haplotypes within the chromosomal region where the carnitine transporter genes map seems to be different between type 1 diabetes patients and healthy controls in our Spanish population. The reduced carnitine plasma levels found in both type 1 and type 2 diabetes patients [12,13] could be explained by a mere increase in the activity of the carnitine transporters to supply the higher energetic cellular demand mainly provided by lipid metabolism in young diabetes patients. However, our results with the $1672{ }^{*} \mathrm{C}$ allele and with the inferred haplotypes, the effect of carnitine sensitizing cells to insulin and potentially rendering them more amenable to an immune attack, and also the LD-block data described by Daly [30], support the role of the OCTN genes in T1D risk. Additional studies in independent populations and in both type 1 and type 2 diabetes patients will be needed to confirm the putative influence of the SLC22A4 and SLC22A5 genes in these diseases.

\section{Abbreviations}

LD Linkage Disequilibrium

MHC Major Histocompatibility Complex
OCTN Organic Cation Transporter

SNP Single Nucleotide Polymorphism

SLC22 Solute Carrier Family 22

T1D Type 1 Diabetes

\section{Competing interests}

The author(s) declare that they have no competing interests.

\section{Authors' contributions}

JLS carried out the genotyping of the patients and a great part of the controls, participated in the statistical analysis and drafted the manuscript.

AM carried out a part of the genotyping of control samples and participated in the statistical analysis.

HdlC made the diagnosis and collaborated in collection of samples.

MAF participated in the genotyping and collection of samples.

MFA participated in the coordination of the study and helped to collect the DNA samples.

EgdlC coordinated the study and critically revised the manuscript.

EU conceived of the study, participated in the statistical analysis and wrote the major part of the manuscript.

All authors read and approve the final manuscript.

\section{Acknowledgements}

We thank Carmen Martínez for expert technical assistance. Alfonso Martínez and Jose Luis Santiago are recipients of FIS contracts (CP04/00I75 and CM05/002 16). Elena Urcelay holds a "Ramón y Cajal" contract of the Spanish Science and Technology Ministry. This work was supported by grant FIS PI05/I22I. 


\section{References}

I. Nerup J, Platz P, Andersen OO, Christy M, Lyngsoe J, Poulsen JE, Ryder LP, Nielsen LS, Thomsen M, Svejgaard A: HL-A antigens and diabetes mellitus. Lancet 1974, 2:864-866.

2. Pociot F, McDermott MF: Genetics of type I diabetes mellitus. Genes Immun 2002, 3:235-249.

3. Field LL: Genetic linkage and association studies of Type I diabetes: challenges and rewards. Diabetologia 2002, 45:21-35.

4. Davies JL, Kawaguchi Y, Bennett ST, Copeman JB, Cordell HJ, Pritchard LE, Reed PW, Gough SC, Jenkins SC, Palmer SM, et al:: A genome-wide search for human type I diabetes susceptibility genes. Nature 1994, 37 I:130-136.

5. Anjos S, Polychronakos C: Mechanisms of genetic susceptibility to type I diabetes: beyond HLA. Mol Genet Metab 2004, 8 I: I87-195.

6. Ramsay RR: The carnitine acyltransferases: modulators of acyl-CoA-dependent reactions. Biochem Soc Trans 2000, 28: I82-186.

7. Foster DW: The role of the carnitine system in human metabolism. Ann N Y Acad Sci 2004, I 033: I- I6.

8. Proulx F, Lacroix J, Qureshi IA, Nadeau D, Gauthier M, Lambert M: Acquired carnitine abnormalities in critically ill children. Eur J Pediatr 1997, 156:864-869.

9. Okuda Y, Kawai K, Murayama Y, Yamashita K: Postprandial changes in plasma ketone body and carnitine levels in normal and non-insulin-dependent diabetic subjects. Endocrinol Jpn 1987, 34:4I5-422.

10. Pregant P, Kaiser E, Schernthaner G: No effect of insulin treatment or glycemic improvement on plasma carnitine levels in type 2 diabetic patients. Clin Investig |993, 7 I:6 I0-6I 2.

II. Tamamogullari N, Silig Y, Icagasioglu S, Atalay A: Carnitine deficiency in diabetes mellitus complications. J Diabetes Complications 1999, | 3:25 |-253.

12. Soltesz G, Melegh B, Sandor A: The relationship between carnitine and ketone body levels in diabetic children. Acta Paediatr Scand 1983, 72:511-515.

13. Winter SC, Simon M, Zorn EM, Szabo-Aczel S, Vance WH, O'Hara T, Higashi L: Relative carnitine insufficiency in children with type I diabetes mellitus. Am J Dis Child 1989, I43:1337-I339.

14. Pregant P, Schernthaner G, Legenstein E, Lienhart L, Bruck S, Schnack $C$, Kaiser E: [Decreased plasma carnitine in Type I diabetes mellitus]. Klin Wochenschr 1991, 69:511-516.

15. Mamoulakis D, Galanakis E, Dionyssopoulou E, Evangeliou A, Sbyrakis S: Carnitine deficiency in children and adolescents with type I diabetes. J Diabetes Complications 2004, I 8:27I-274.

16. Akisu M, Kultursay N, Coker I, Huseyinov A: Myocardial and hepatic free carnitine concentrations in pups of diabetic female rats. Ann Nutr Metab 2002, 46:45-48.

17. Tamai I, Yabuuchi H, Nezu J, Sai Y, Oku A, Shimane M, Tsuji A: Cloning and characterization of a novel human pH-dependent organic cation transporter, OCTNI. FEBS Lett 1997, 4I9: 107-111.

18. Grundemann D, Harlfinger S, Golz S, Geerts A, Lazar A, Berkels R, Jung N, Rubbert A, Schomig E: Discovery of the ergothioneine transporter. Proc Natl Acad Sci U S A 2005, I 02:5256-526I.

19. Tamai I, Ohashi R, Nezu J, Yabuuchi H, Oku A, Shimane M, Sai Y, Tsuji A: Molecular and functional identification of sodium iondependent, high affinity human carnitine transporter OCTN2. J Biol Chem 1998, 273:20378-20382.

20. Tokuhiro $S$, Yamada R, Chang X, Suzuki A, Kochi Y, Sawada T, Suzuki $M$, Nagasaki $M$, Ohtsuki $M$, Ono $M$, Furukawa $H$, Nagashima $M$, Yoshino S, Mabuchi A, Sekine A, Saito S, Takahashi A, Tsunoda T, Nakamura Y, Yamamoto K: An intronic SNP in a RUNXI binding site of SLC22A4, encoding an organic cation transporter, is associated with rheumatoid arthritis. Nat Genet 2003, 35: 34I-348.

21. Peltekova VD, Wintle RF, Rubin LA, Amos CI, Huang Q, Gu X, Newman B, Van Oene M, Cescon D, Greenberg G, Griffiths AM, St George-Hyslop PH, Siminovitch KA: Functional variants of OCTN cation transporter genes are associated with Crohn disease. Nat Genet 2004, 36:47I-475.

22. Smyth DJ, Howson JM, Payne F, Maier LM, Bailey R, Holland K, Lowe CE, Cooper JD, Hulme JS, Vella A, Dahlman I, Lam AC, Nutland S, Walker NM, Twells RC, Todd JA: Analysis of polymorphisms in I 6 genes in type I diabetes that have been associated with other immune-mediated diseases. BMC Med Genet 2006, 7:20.
23. Stefan Schneider DRLE: Arlequin: A Software for Population Genetics Data Analysis. 2.0002000 [http://anthro.unige.ch/arle quin]. Geneva, University of Geneva

24. Barton A, Eyre S, Bowes J, Ho P, John S, Worthington J: Investigation of the SLC22A4 gene (associated with rheumatoid arthritis in a Japanese population) in a United Kingdom population of rheumatoid arthritis patients. Arthritis Rheum 2005. 52:752-758.

25. Martinez A, Valdivia A, Pascual-Salcedo D, Balsa A, Fernandez-Gutierrez B, De la Concha E, Urcelay E: Role of SLC22A4, SLC22A5, and RUNXI genes in rheumatoid arthritis. J Rheumatol 2006, 33:842-846

26. Martinez A, Del Carmen Martin M, Mendoza JL, Taxonera C, DiazRubio M, de la Concha EG, Urcelay E: Association of the organic cation transporter OCTN genes with Crohn's disease in the Spanish population. Eur J Hum Genet 2006, 14:222-226.

27. Nerup J, Pociot F: A genomewide scan for type I-diabetes susceptibility in Scandinavian families: identification of new loci with evidence of interactions. Am J Hum Genet 200I, 69: |30|-|3. Epub 200| Oct II.

28. Lindgren CM, Widen E, Tuomi T, Li H, Almgren P, Kanninen T, Melander O, Weng J, Lehto M, Groop LC: Contribution of known and unknown susceptibility genes to early-onset diabetes in scandinavia: evidence for heterogeneity. Diabetes 2002, 5 I: 1609-1617.

29. UCLA Department of Statistics. [http://calculatorsstatuclaedu/ powercalc] .

30. Daly MJ, Rioux JD, Schaffner SF, Hudson TJ, Lander ES: High-resolution haplotype structure in the human genome. Nat Genet 2001, 29:229-232.

\section{Pre-publication history}

The pre-publication history for this paper can be accessed here:

\section{http://www.biomedcentral.com/1471-2350/7/54/prepub}

Publish with BioMed Central and every scientist can read your work free of charge

"BioMed Central will be the most significant development for disseminating the results of biomedical research in our lifetime. "

Sir Paul Nurse, Cancer Research UK

Your research papers will be:

- available free of charge to the entire biomedical community

- peer reviewed and published immediately upon acceptance

- cited in PubMed and archived on PubMed Central

- yours - you keep the copyright
BioMedcentral 